\title{
La dominación española en El triunfo de la libertad sobre el despotismo (1817) del venezolano Juan Germán Roscio
}

\author{
Carmen RUIZ BARRIONUEVO \\ Universidad de Salamanca
}

\begin{abstract}
RESUMEN
La obra del venezolano, Juan Germán Roscio, apenas estudiada hasta el momento, recoge el pensamiento vigente en los comienzos de la emancipación y analiza los problemas fundamentales que impedían la total libertad de los países de América de la dominación española. El triunfo de la libertad sobre el despotismo concentra su ideario en el estudio de las Escrituras para establecer la soberanía del pueblo y rechazar del poder divino de los monarcas, así como, en último extremo, el apoyo del regicidio como derecho de los pueblos frente a gobiernos tiránicos y despóticos. Roscio registra las características de la dominación española, encarnada en el absolutismo del poder real que legitima la Iglesia con el monopolio y exclusivismo de la interpretación de los textos sagrados.
\end{abstract}

Palabras clave: Literatura venezolana, independencia venezolana, Juan Germán Roscio, El triunfo de la libertad sobre el despotismo.

The Spanish Domination in El triunfo de la libertad sobre el despotismo (1817) over the Venezuelan Juan Germán Roscio

\begin{abstract}
The work of the Venezuelan, Juan Germán Roscio, hardly studied so far, includes the thought existing at the beginning of emancipation and analysis of the fundamental problems that impeded the full freedom of the countries of the Americas of Spanish domination. El triunfo de la libertad sobre el despotismo concentrated their ideology in the study of scripture to establish the sovereignty of the people and rejecting the divine power of the monarchs, as well as, ultimately, the support of the regicide as a right of peoples to tyrannical and despotic governments. Roscio records the characteristics of the Spanish domination, embodied in the absolutism of the real power that legitimizes the Church with the monopoly and exclusivity of the interpretation of sacred texts.
\end{abstract}

Keywords: Venezuelan literature, Venezuelan independence, Juan Germán Roscio, El triunfo de la libertad sobre el despotismo. 
En 1817 apareció en Filadelfia una de las obras más importantes y sorprendentes de la emancipación venezolana, El triunfo de la libertad sobre el despotismo. Era su autor Juan Germán Roscio (1763-1821) y en ella condensaba de excepcional y original forma su pensamiento acerca de los problemas fundamentales que impedían la total libertad de los países de América de la dominación española. Hijo de milanés y de mestiza, ingresó en la Universidad de Caracas, gracias a la protección de doña María de la Luz Pacheco, hija del Conde de San Javier, ya que su origen social le hubiera impedido el ingreso directo. Consiguió así ser bachiller y doctor en Cánones, y luego brevemente, catedrático de Instituta en la misma Universidad en 1798, para doctorarse en Derecho Civil en 1800. Roscio contempló en primera fila los acontecimientos que prepararon la emancipación venezolana, como la conspiración de Gual y España en 1797 y sobre todo el movimiento del 19 de abril de 1810, donde fue designado Diputado por el Pueblo y Secretario de Relaciones Exteriores de la Junta Suprema de Caracas. Poco más tarde redactará con Francisco Isnardi el acta de independencia del 5 de julio de 1811, "Manifiesto que hace al Mundo la Confederación de Venezuela". Es a partir de este momento en el que empieza a desplegarse su pensamiento a través de escritos varios, cartas y textos breves hasta desembocar en su magna obra El triunfo de la libertad sobre el despotismo.

La ideología de Roscio se comienza a manifestar en estos textos iniciales y sobre todo en el titulado "Patriotismo de Nirgua y abuso de los reyes" publicado en el Gaceta de Caracas ${ }^{2}$, que Domingo Miliani considera "el antecedente conceptual y estructural inmediato de El triunfo de la libertad sobre el despotismo" pues en él se aprecia su ideario basado en "la refutación del poder divino de los monarcas" y apoyo del regicidio, así como también la "revocabilidad como derecho de los pueblos frente a gobiernos que no cumplen con sus obligaciones de conceder protección, y bienestar" a sus pueblos (Miliani en Roscio: XXI). Desde luego que, considerando la estructura del texto que adopta la forma de una carta oficial, Roscio parte del mismo hilo conductor que después, con más extensión y profundidad, desarrollará en su magna obra: el arrepentimiento del pecador que ha enderezado su camino para dirigirse a la verdad. En esa línea constatará que Nirgua, "desengañada por la ilustración y patriotismo de su vecina la ciudad de San Felipe, volvió al camino de la verdad, juró su independencia con demostraciones muy distinguidas" (Pensamiento: 66). El texto adopta por tanto la forma de una comunicación administrativa en la que se exalta el comportamiento del pueblo que arrojó en la plaza pública "el retrato y armas de Fernando, el hijo de María Luisa, y el pendón que, como monumentos de ignominia y servidumbre, permanecían en la sala de ese cuerpo capitular" (Pensamiento: 67). Tal gesto capitaliza el rechazo a la idolatría de los reyes

${ }^{1}$ El texto puede consultarse en Pensamiento: 261-294. Es evidente que varios de los argumentos esgrimidos, apoyados en textos bíblicos, coinciden con los del libro que comentamos.

2 Juan Germán Roscio, "El Patriotismo de Nirgua y abuso de los Reyes", está datado en el Palacio Federal de Venezuela, a 18 de septiembre de 1811. 
auspiciada por el clero antiliberal, tanto en España como en América, y se propone en el texto del autor como centro de la diana y mal a combatir contra la imposición de los eclesiásticos que ocultaban el "vicioso origen de los reyes, langostas del género humano" (Pensamiento: 67). El problema radicaba en la arraigada convicción existente en los pueblos hispanos, de la inevitable y necesaria sumisión a los monarcas, que encarnaban un poder divino fomentado y acrecido interesadamente por la Iglesia ${ }^{3}$. Por tanto para Roscio la España del momento está encarnada en ese absolutismo que legitima la Iglesia con el monopolio y exclusivismo de la interpretación de los textos sagrados, que al mismo tiempo dan cobertura al poder real. El venezolano establece aquí ya su método futuro: demostrar que tanto en el Antiguo Testamento como en los pueblos de Grecia y Roma no fueron necesarios los reyes en la mayor parte de su historia, aún más, "El pésimo ejemplo de los gentiles dominados todos por reyes y a la sombra de la idolatría inficionaba muchas veces a los hebreos y los inducía a este pecado" (Pensamiento: 71), y de modo opuesto, "El gobierno republicano fue el primero porque es más conforme a la naturaleza del hombre" (Pensamiento: 68), ya que además de ello se deriva una idea de suma importancia, la igualdad de los hombres, "Dios no crió reyes ni emperadores, sino hombres hechos a imagen y semejanza suya" (Pensamiento: 68), para quien como Roscio, ilustrado pero creyente, defendió como abogado las desigualdades de la sociedad ${ }^{4}$.

De este modo en este primer texto, la España del momento, dominada por un pensamiento absolutista, contradice para el autor las mismas Escrituras porque la doctrina de Jesucristo "era una declaración de los derechos del hombre y de los pueblos" (Pensamiento: 73) y ha sido tergiversada en su sentido por una Iglesia que apoyaba a los reyes en sus tiranías, aún más, se han silenciado los textos que en la Biblia defienden la soberanía del pueblo, como el discurso del profeta Samuel contra los reyes, y en cambio la propia Iglesia ha elaborado decretos y censuras a favor de una monarquía despótica haciéndolos valer ante sus fieles en la enseñanza y en la predicación.

Coincidiendo con estas fechas y los dos años subsiguientes, de 1810 a 1812 , Roscio mantiene relación epistolar desde Caracas con Andrés Bello residente entonces en Londres, y algunas de las cartas que se conservan resultan significativas en relación con este pensamiento. Así el 29 de junio de 1810 reflexiona sobre las noticias que llegan de España y que sin embargo no repercuten en la resuelta decisión emancipadora de sus conciudadanos, pues con una península dominada por las tropas

${ }^{3}$ Este ambiente de credulidad y fanatismo religioso existente a fines del siglo XVIII, no muy lejano del que se vivía en España, es descrito por Pino Iturrieta (24-47) con el apoyo de los testimonios de viajeros como J. J. Dauxion Lavaysse, Francisco Depons y Humboldt.

4 "Roscio actúa contra el Cabildo de Valencia, como defensor de la mestiza Isabel María Páez, esposa de Juan José Ochoa, a quien se niega el derecho de usar alfombra para arrodillarse en el templo, pues era éste un privilegio reservado sólo a las mujeres mantuanas" (Citado por Miliani en Roscio: 265). 
francesas todavía algunos intrigan a favor de la sumisión al rey y se niegan a reconocer otra autoridad que la que emana de la península. Justo en esa carta el jurista venezolano expone dos temas que le interesan relacionados con el momento de la independencia: el tema de la donación papal y el de la temida cesión de los territorios del continente a los monarcas franceses. En efecto, Roscio recuerda la bula de Alejandro VI y el título $1^{\circ}$, libro 3 de la Recopilación de Indias ${ }^{5}$, y con gran ironía deduce que "su concesión es limitada a los reyes don Fernando y doña Isabel, a sus descendientes y sucesores legítimos; no comprende el donativo a los peninsulares, ni a la Península, ni a la isla de León, ni a los franceses", con lo que saca una lógica consecuencia que favorece sus intereses: "Por consiguiente, faltando ellos y sus legítimos herederos y sucesores, queda emancipada y restituida a su primitiva independencia", (Bello: 9), y en todo caso, añade, los sucesores están "representados ahora en nosotros". En cuanto a la segunda posibilidad, la de la enajenación de esas tierras a dominio francés, Roscio reprocha la vileza de los reyes españoles que cedieron con actos contrarios a derecho en las abdicaciones de Bayona, considerando además que proceden de una dinastía, la de los Borbones, que obtuvo el privilegio del reino en la guerra de Sucesión con el apoyo del pueblo español, ante el que adquirieron responsabilidades de defensa y seguridad. Y, sin embargo, en vez de sacrificar su vida ante la opresión francesa, su actuación ha sido tan vil e inepta que no debieran "contribuir de ningún modo a cedernos y adjudicarnos al imperio de Francia, como si nosotros fuésemos ganados y bestias vendibles y comerciables a discreción y voluntad del propietario que las posee" (Bello: 37). De ahí que por semejantes actuaciones de los monarcas españoles los americanos deberán quedar libres cuanto antes de cualquier juramento de fidelidad al rey y "formar el Gobierno que más importase a nuestra felicidad" (Bello: 38 ).

La segunda carta dirigida a Bello que tiene que ver con este tema, precede a la anterior, pues está fechada el 10 de septiembre de 1810, y comienza haciéndose eco de las noticias que difunden los dos primeros números de El Español, periódico que José María Blanco White (1775-1841) editaba en Londres: "Ese periódico trae muy buenas cosas en favor de nuestra causa" (Bello: 14) anota con decisión ${ }^{6}$, luego pasa a

\footnotetext{
${ }^{5}$ En efecto en el Libro 3, Título $1^{\circ}$, "Del dominio y jurisdicción real de las Indias" se dice: "Por donación de la Santa Sede Apostólica y otros justos y legítimos títulos, somos Señor de las Indias Occidentales, Islas y Tierra Firme del mar Océano, descubiertos, y por descubrir, y están incorporados en nuestra Real Corona de Castilla. Y porque es nuestra voluntad, y lo hemos prometido y jurado, que siempre permanezcan unidas para su mayor perpetuidad y firmeza, prohibimos la enajenación de ellas". (Recopilación de leyes de los Reynos de las Indias, mandadas imprimir y publicar por la Magestad Católica del Rey Don Carlos II Nuestro Señor, En Madrid, por Julián de Paredes, 1681, 4 vols.)

${ }^{6}$ Refiriendo la importancia del periódico de Blanco White, Juan Goytisolo comenta: "El Español reflejaba así las diversas opciones y doctrinas políticas del momento, del pragmatismo liberal de Juan Germán Roscio, afín a su redactor, hasta las posiciones más próximas al populismo democrático de Miranda y Bolívar" (Goytisolo: 40). A partir de estas
} 
describir alguno de los contenidos, sobre todo el dictamen de la Universidad de Sevilla y el manifiesto de la Junta Central de Aranjuez ${ }^{7}$, acerca de los cuales afirma que si el pueblo español se ha reconquistado a sí mismo, en ausencia del poder real y de sus autoridades, "estaba en libertad para establecer el sistema de Gobierno que más le conviniese" (Bello: 14). Es evidente que Roscio establece enseguida el paralelismo con la situación americana, para insistir en los altibajos y veleidades de los reyes que en 1795 firmaron la paz de Basilea con alianzas con el invasor francés al ceder la isla de Santo Domingo. Recordemos que en aquella ocasión se entregó también la Luisiana, pero a Roscio le preocupa en mayor medida la isla caribeña, con la que los venezolanos de la época tenían mayor relación, por lo que comenta: "Entonces contra la ley $1^{\text {a }}$ título $1^{\circ}$ libro $3^{\circ}$ de la Recopilación Indiana fue cedida la isla española de Santo Domingo en lugar de las plazas conquistadas en la península; y nadie reclamó la transgresión de esta ley" (Bello: 15). Este tema de la impunidad con la que los reyes y los papas, confundiendo el altar y el trono, habían dispuesto desde la llegada de Colón del territorio americano aparece como obsesivo en sus obras. Es evidente que para el autor venezolano es un acto contrario, no sólo a los Derechos del hombre y del ciudadano difundidos por la Revolución francesa, sino al Derecho natural y a la propia razón crítica esgrimida por los ilustrados. Ya en "El patriotismo de Nirgua" se advertía un intento de rebatir el procedimiento de la "donación papal" como justificación del derecho de propiedad de los territorios por descubrir ("en el siglo XV [hubo] un Papa que se atrevi[ó] a donar a los reyes de Castilla un mundo que no era suyo, ni de la silla apostólica" en lugar de continuar el legado de Jesucristo. Pensamiento: 77). Debate pues Roscio el derecho de conquista ejercido con violencia a los pueblos bárbaros que se había instaurado en una época, como el siglo XVI, en la que se imbricaban los temas jurídicos y los teológicos, y acerca de lo cual surgieron algunas controversias entre juristas y teólogos ${ }^{8}$. En todo caso tal derecho, insiste, sólo puede durar el tiempo que los usurpadores ejercen esa fuerza, ya que cuando "los conquistados adquieren suficientes fuerzas o coyunturas con que recuperar la carta de sus derechos usurpados, ellos pueden y deben restituirse a su primitivo estado de independencia y libertad" (Pensamiento: 79).

Es lógica la deducción de que ante la incierta situación histórica, Roscio temiera el hábito que los españoles americanos tenían por la antigua servidumbre y cedieran por la fuerza al capricho y antojo de sus gobernantes rindiéndose al intruso gobierno francés, con lo que, siguiendo la misma suerte que España, "serían más esclavos los

fechas Blanco White y Roscio tendrían una amistad que se nos evidencia en algunas misivas y en textos de El Español.

${ }^{7}$ El número 2 de El Español, aparecido el 30 de mayo de 1810, se abría con el "Dictamen sobre el modo de reunir las Cortes de España" que Roscio comenta; también se refiere a las noticias que aparecen en el apartado "Noticias de España" (Blanco White: 67-79; 118-129).

${ }^{8}$ Las discusiones y polémicas en torno a este derecho han sido estudiados especialmente por Silvio Zavala en varios de sus trabajos, como Ensayos sobre la colonización española en América y Por la senda hispana de la libertad (Véase Zavala, 1944: 27-61; 1992: 17-69). 
españoles americanos, porque tenían dos señores a quien servir: señores franceses, y señores españoles" (Bello: 15).Y llega a concluir cobrando nuevos bríos y seguridad en el rechazo de cualquier dominación francesa: "En cualquiera de estos casos serán frustrados los designios del Tirano, y aunque vuelva Fernando no será admitido, siempre que venga bajo el influjo, alianza, o dependencia de Napoleón" (Bello: 16). En realidad bajo tales cavilaciones subyacía una de las convicciones más arraigadas entre los ilustrados que era la importancia de la educación para todo ser humano y como consecuencia, que la falta de información conllevara esos peligros. Su pensamiento en este apartado estaba ligado a su indudable lectura de Rousseau, que sin duda había circulado ampliamente entre los criollos americanos, aunque como es sabido, había sido perseguida en todo el ámbito hispánico ${ }^{9}$ y una de cuyas obras cita en carta a Bello. Por tanto para Roscio, como buen ilustrado, la falta de educación producía ignorancia en el ciudadano, lo sumía en el error, el fanatismo y en el temor, en este caso aceptando cualquier sumisión a decisiones arbitrarias de los monarcas a los que se creía infundidos de carácter divino.

Todos estos temas aquí esbozados aparecen concentrados en su libro El triunfo de la libertad sobre el despotismo en el que formalmente se exhibe una deliberada escisión del sujeto para marcar, con la pauta de las Confesiones de san Agustín, un antes y un después de su vida ${ }^{10}$. La retórica petitio benevolentiae esboza una conexión tanto con las guías de pecadores como con los libros de pecadores arrepentidos, en los que se elabora una conversación directa con Dios. Esta aproximación es muy visible en el subtítulo: "En la confesión de un pecador arrepentido de sus errores políticos, y dedicado a desagraviar en esta parte a la religión ofendida con el sistema de la tiranía", pues por un lado existe un juego dialogante con el Salmo 50 de David ${ }^{11}$,

${ }^{9}$ En carta a Andrés Bello le dice: "Acuérdese usted de que Londres fue el lugar donde escribió el padre Viscardo su Legado, y donde obtuvo la mejor apología el Contrato Social de Rousseau" (Bello: 10). Abrió los estudios acerca de este tema el libro ya clásico de Jeffferson Rea Spell, Rouseau in the Spanish World Before 1833, Austin, University of Texas Press, 1938.

10 “Adopté el método de confesión, imitando las de San Agustín, por haberme parecido el más propio y expresivo de la multitud de preocupaciones que me arrastraban en otro tiempo" (Roscio: 5) Más adelante dirá: "Menos por malicia que por ignorancia, abusaba de la Religión para sostener la servidumbre de mi patria. Yo fui uno de los que en 1806, tomaron armas y pluma para destruir a los buenos que intentaban conquistar mi libertad y la de mis hermanos [...] Me avergüenzo del servicio especial que hice yo entonces y del mérito que contraje en la opinión del déspota y sus satélites [...] A mucho honor tenía ser esclavo y muy adicto al tirano" (Roscio: 234).

${ }^{11}$ Precisamente Diego José de Cádiz (1743-1801), al que el autor citará en su obra, es autor de Afectos de un pecador arrepentido en místicas décimas formadas con los soliloquios, que ante Jesús Crucificado acostumbra hacer en sus Misiones..., Fr. Diego Joseph de Cádiz, Misionero Apostólico Capuchino, para excitar las almas à contrición de sus culpas. SevillaJaén, Pedro Doblas, 1791-1974. 
("Misericordia, Dios mío, por tu bondad, / por tu inmensa compasión borra mi culpa; / lava del todo mi delito, / limpia mi pecado") con un desplazamiento laico hacia otro ámbito, el político, en neta confluencia con el religioso, tal y como hemos visto en el anterior texto, pero que se explicita aún más en esta obra. Así Roscio hace alusión a la situación de España en torno a 1814 después del fracaso de la Constitución al mismo tiempo que expresa sus ideas teóricas acerca de la emancipación.

El libro puede considerarse, entonces, de origen confesional según el modelo religioso, pero traspuesto al terreno laico, en tanto que el autor aprovecha su convicción realista al servicio de la Corona hasta 1809, y el posterior arrepentimiento, al que se refiere con alguna ironía empleando el correlato religioso de las Confesiones. En el fondo el venezolano asumía y ejemplificaba el proceso de la mayor parte de los criollos ante la situación por la que atravesaba la corona española pues en principio no dejaron de apoyarla para separarse, en vista de la situación, progresivamente de ella. Por eso en el Prólogo se hace eco del fracaso de la Constitución y cómo no existe otra posibilidad que la emancipación, ya que España "Liberal, sin duda, con el territorio de la Península, con las islas Baleares y Canarias, era muy mezquina con los países de ultramar en cuanto al derecho de representación" (Roscio: 3). Prólogo e Introducción son dos textos que tienen parecida funcionalidad. $\mathrm{Su}$ objetivo es plantear la defensa de la libertad y el derecho de los pueblos a su emancipación prescindiendo del origen divino de los reyes. Para ello se fundamenta en los libros religiosos al igual que lo practicaban los clérigos absolutistas y antiberales en sus escritos y sermones. Pero en este caso haciendo ver que, al contrario, en estos libros sagrados se defiende la soberanía del pueblo, que la lectura ha sido manipulada por la tradicional interpretación de la iglesia. Es así como en la misma lectura de la Biblia encontrará argumentos sólidos para rebatir las tesis establecidas. Para ello establece un método riguroso que mucho tiene que ver con su formación académica, aunque infundiendo distinto sesgo, pues incluía una lectura muy proclive a la practicada por los protestantes. Esa interpretación es percibida por González Ordosgoitti (210-216) al hablar de cómo el autor realiza una interpretación "hermenéutica de la Biblia" que contradecía la vigente en el catolicismo de su época. En efecto, las palabras del prócer venezolano en su libro lo dejan bien claro:

Me dediqué al estudio de la Vulgata, no en los indigestos y dolosos comentarios que me llenaron el tiempo, mientras yo cursé la cátedra de escritura, sino como debieron estudiarla los autores de ellos, y como la estudia quien no está consagrado en cuerpo y alma al servicio de la tiranía (Roscio: 4).

Es así como Roscio, convencido cristiano, adelantará su conclusión: que no hay ninguna "ley del nuevo y viejo Testamento que favoreciese la opresión" (Roscio: 4) porque los usos de la monarquía absoluta y despótica no pueden conciliarse con el cristianismo. Sin embargo, ello no impide que el "pecador arrepentido" capitalice los errores de todos asumiendo su "pecado" y concentrándolo en la frase que lo resume: "mientras yo seguía las banderas del despotismo" (Roscio: 7) ya que 
Yo desconocía el idioma de la Razón. La práctica de los pueblos ilustrados y libres era en mi concepto una cosa propia de gentiles, y ajena de cristianos: detestaba como heréticos los escritos políticos de los filósofos. Por los malos hábitos de mi educación yo no conocía otro derecho natural que el despotismo, otra filosofía que la ignorancia, ni otra verdad que mis preocupaciones" (Roscio: 7).

Se aprecia cómo el prócer venezolano es partidario de la interpretación libre de las Escrituras y niega como fraudulenta la interpretación impuesta que ha permitido el triunfo de los regímenes despóticos, en los que se han seleccionado algunos libros, sobre todo el Nuevo Testamento, olvidando otros que, como los libros de Moisés, Josué, Jueces, Reyes, Paralipómenon, Esdras, Nehemías y los Macabeos se referían a temas políticos, canonizando así "la más escandalosa usurpación" (Roscio: 8). Por eso se preguntará creyendo siempre en los fines espirituales de Jesucristo, “¿Por qué recurrir a preceptos o consejos evangélicos para defender y santificar la tiranía de los monarcas absolutos?" (Roscio: 9). Es así como entiende que con estas interpretaciones llegó a venerarse al tirano y llegaron a calificarse de irreligiosos a todos los que rechazaban esa imposición. Con ello se ha construido "el triple yugo de la monarquía absoluta, del fanatismo religioso y de los privilegios feudales" porque en la situación actual quien obedece al rey obedece a Dios, aunque él mismo se confesara parte de esta situación: "Yo mismo incurrí en esta infamia en 1797 y 1806 " (Roscio: 10). Como bien ha señalado Morales Pino, Roscio insistirá en los desplazamientos semánticos de los términos y hará valer la múltiple interpretación, de tal modo que su propuesta no deja de tener matices de subversión:

El enfoque crítico con el que Roscio aborda el texto sagrado da lugar a una lectura subversiva y contestataria de las Escrituras, pues a través de esta innovadora aproximación al discurso bíblico le es posible alcanzar un significado contrario al establecido por el poder en su autolegitimación (Morales Pino: 12)

Los cincuenta y un breves capítulos del libro dan nuestra del excelente manejo que el autor venezolano tenía de las Escrituras pues su apoyatura exclusiva la constituirán muy especialmente los libros sagrados, de los que extraerá una serie de conceptos políticos que además coincidirán con algunas de las máximas de los Derechos del hombre y del ciudadano". De los Proverbios de Salomón el autor deduce que "El hombre es naturalmente libre; no puede ser privado de su libertad sin justa causa" (Roscio: 15), e irá pasando a otros libros como el de la Sabiduría, o el capítulo 14 de

${ }^{12}$ El texto lo tradujo Juan Bautista Picornell y es probable que se publicara en Guadalupe en 1797, fue un impreso perseguido que los mantuanos volvieron a publicar en 1811 (Véase Pino Iturrieta: 139-146). Varias veces se alude a la libertad en estos Derechos, así en el apartado IX, "La ley debe proteger, así la libertad pública como la de cada individuo en particular, contra la opresión de los que gobiernan"; XXV, "La soberanía reside en el Pueblo: es una e indivisible, imprescriptible e inalienable" (Pensamiento: 32-35). 
los Proverbios del que se infiere que "En la muchedumbre del pueblo está la dignidad del Rey, y en su pequeñez la ignominia del príncipe" (Roscio: 23). Pero la principal idea que desea sustentar es el concepto de soberanía, fundamento de la capacidad de autogobierno de los nacidos en América. Advertimos que son muchos los capítulos encadenados que le dedica al tema, del tres hasta el quince, y que siguiendo la misma pauta de la conversión religiosa, el concepto se introduce con alguna ironía: "Imaginaba yo que la soberanía era una cosa sobrenatural e invisible, reservada desde la eternidad para ciertos individuos y familia, e íntimamente unida con la palabra Rey" (Roscio: 24), con lo cual ciertas personas adquirían una cualidad espiritual y de origen divino, de manera que ese carácter los exoneraba del cumplimiento de las leyes a la vez que podían dispensarlas a su voluntad. Es evidente que esta idea troncal de su libro la recoge Roscio de fuentes ilustradas, no sólo, como hemos indicado de los Derechos del hombre y del ciudadano, sino de su lectura apasionada de Rousseau: "Soberanía es el resultado del poder y de la fuerza moral y física de los hombres congregados en sociedad" (Roscio: 27), pues el hombre no es un ser solitario sino libre y racional que necesita la comunidad: los hombres se reúnen y acompañan, y "cada socio pone por capitales aquellas virtudes intelectuales y corporales, que sirven de materia al contrato social" (Roscio: 28). Consciente de que la soberanía es algo propio de todos los hombres, necesitará fundamentarla con solidez para destruir la exclusividad del poder real de España en América.

Hoy día pueden resultar enfadosas tantas argumentaciones de las Escrituras en un libro que persigue un fin político y laico, pero sin duda que su autor las creyó oportunas en su momento, no sólo por la formación escolástica y teológica que había recibido, sino por sus creencias y convicciones. En todo caso sorprende que "Lejos de apelar a argumentos racionales para desmontar el discurso absolutista y el derecho divino de los reyes, Roscio acude a la Biblia en la medida en que entiende que ha sido ésta la fuente primordial empleada en la legitimación de tal sistema político" (Morales Pino: 33). Por eso no evita interpretaciones de diversos apartados del Génesis, de las historias de Abraham y Jacob, de Moisés ("Sacando del Egipto a los Hebreos, los reintegró a su soberanía" Roscio: 39). En definitiva es en el pueblo en el que reside la soberanía, algo que no admite la Iglesia y cuya voz capitalizan los clérigos absolutistas y antiliberales como el autor de un folleto aparecido en 1814 al que alude la primera vez sin nombrarlo que "enseñaba ser peculiar de los Reyes el poder y la fuerza" (Roscio: 116). Páginas más adelante concretará más los datos:

Este impreso es uno de los muchos que han salido de las prensas de Madrid después del 4 de Mayo de 1814, en apoyo de la tiranía. Es un volumen compuesto de varias cartas, que se dicen escritas por Fr. Diego de Cádiz a un sobrino suyo, que militaba en la Península contra los ejércitos de la República Francesa instruyéndole él las obligaciones de un soldado cristiano (Roscio: 197).

Es relevante la cita porque Roscio, con gran acierto y conocimiento, se refiere a Fray Diego José de Cádiz (1743-1801), como representante del clero reaccionario de la época. Misionero capuchino, recorría los lugares de España aferrado a la 
intransigencia en materias de doctrina y moral. Su influyente oratoria, en una sociedad carente de educación, defendía el absolutismo frente a cualquier asomo liberal en ideas y costumbres. Muy difundido en su época por su predicación y con gran ascendiente en las multitudes, debía ser harto conocido para el venezolano que además pasó algún tiempo preso en Cádiz y Ceuta entre 1813 y 1815. Fray Diego atacó, tanto a las instituciones de la Corona, como a las que asumían algún progreso, que pensaba contagiado de los revolucionarios franceses a los que consideraba "hijos de Lucifer". Fue, en definitiva, un excelente representante del clero absolutista y reaccionario de la época, y aunque fue perseguido por los mandatarios también salió triunfante y fue apoyado por sus seguidores. No se engañaba Roscio al indicar "Yo no sé por qué causa han estado inéditas estas cartas desde 93 o 94 del siglo pasado hasta 1814" (Roscio: 198). En efecto, Fray Diego escribió el texto que comenta en la guerra franco-española del Rosellón (1793-1795) que terminó degradantemente para España con la Paz de Basilea, para ella escribió este libro El soldado católico en guerra de religión ${ }^{13}$, Barcelona, 1794 (dirigido en forma de carta a su sobrino Antonio, enrolado como voluntario). Recuperado posteriormente por su actualidad será esgrimido por sus partidarios de 1808 a 1814 en la lucha contra los ejércitos napoleónicos.

Muchas de las ideas del libro debieron ofender al venezolano pues en él se exhibe una total confusión entre la misión bélica y política del soldado y su relación con la fe, así, en un momento determinado se señala que la deserción se parangona con la apostasía de la fe religiosa, pero Roscio únicamente extrae una de las frases en las que se enfatiza la relación con el rey desde esa perspectiva de su carácter divino: "No quedará sin castigo (dice el texto), quien ofendiere al Rey, aunque no sea más que con el pensamiento" (Roscio: 198), ya que afectaba directamente al tema de la soberanía del pueblo que el autor sustentaba en su libro. Que el folleto le había impactado lo prueba el que vuelva a citarlo en el artículo titulado "Catecismo" que publica en el Correo del Orinoco en 1819 y cuyo texto fue rescatado por Pedro Grases ${ }^{14}$. Y siguiendo con el mismo pensamiento recuerda otros libros especialmente nefastos que difundían las mismas ideas como es el caso de un manual de estudio del que no quiere recordar el autor: "en materia de su contenido adolecía yo de un error que aprendí en cierta obra titulada Derecho público de las naciones. Bajo esta corteza no había en ella más que dogmas del poder arbitrario" (Roscio: 210) ${ }^{15}$.

${ }^{13}$ Las primeras ediciones aparecieron en 1794 en Écija y Barcelona. Fue recuperado en la guerra de la independencia y al menos se conservan ediciones de los años 1813 en Cádiz, 1814 en Madrid, y 1815 en Córdoba. Hemos consultado la siguiente edición: El soldado católico en guerra de religión. Carta instructiva ascética-histórico-política. Reimpreso en Málaga por los Herederos de D. Francisco Martínez de Aguilar, Reimpreso en Cádiz en la Casa de Misericordia, Año 1813.

${ }^{14}$ En este breve texto Roscio reflexiona: "Son innumerables los impresos que salían de la Corte y demás prensas filiales contra la libertad nacional. Parecía que las cartas del P. Cádiz deberían cerrar la feria de estos escritos" (Grases: 17).

${ }^{15}$ Roscio ingresó en 1798 en la Academia de Derecho Público que muy pronto se intentó convertir en Cátedra. "A partir del segundo año se estudiarían los textos legales, especialmente 
A partir del capítulo XVI del libro se despliegan otros conceptos como el de libertad, derecho y ley, palabras que Roscio considera adulteradas en el presente de las monarquías absolutas y que cree necesitadas de un mayor centramiento en su significado, a la vez que se ha ido creando otro vocabulario pervertido para inmovilizar y oprimir al pueblo. Frecuentemente, ante la ausencia de libros que avalen estas experiencias, aduce la propia confesión según la cual se difundía la veneración al rey como "Señor de vidas y haciendas". Y aclara: "Desde la cocinera de mi casa, hasta el cura de mi parroquia era tan trivial esta doctrina, que no podía menos de llegar muy luego al conocimiento de niños. "Al Rey y la inquisición, chitón"” (Roscio: 224). Es así como advierte que se organiza un engranaje que se superpone a la sociedad: "Todo el mecanismo de la tiranía se llama administración paternal, y divina" (Roscio: 123) dice con convicción, porque para Roscio consciente ilustrado, la ley no puede derivar de un único individuo, porque carece de legitimidad, y si se da tal situación se produce esclavitud, con lo que todo hombre debe resistirse a una ley que no sea el resultado de la voluntad del pueblo y en ello se fundamenta la libertad. En cambio, "La libertad, madre y nodriza de las virtudes sociales es irreconciliable con el despotismo (Roscio: 76), incluso los israelitas buscaron recobrar su libertad. Hasta tal punto que, si en el antiguo régimen se juzgaba criminal el resistir al déspota, en cambio ello no es censurable en situación de esclavitud porque se puede ejercer la fuerza contra el rey para obtener la libertad. Todo es lícito para los ciudadanos a la hora de romper la tiranía pues el rey no posee ese carácter divino; "lícito es quitar la vida al injusto agresor, rechazar la fuerza con la fuerza, salvar con ella a los que se hallan en angustia y peligro indebidos" (Roscio: 133), para ello se apoya en la Escritura y Santo Tomás como se explicita en el Capítulo XLVII, "Continúa la materia del regicidio y tiranicidio", y en el siguiente titulado "Se concluye la materia del regicidio y tiranicidio".

En cambio el autor apoya a los reyes constitucionales y al presidente de Estados Unidos: "Los amo, los honro y reverencio como representantes de una nación soberana" (Roscio: 226) porque, como buen ilustrado, no encuentra más fundamento para la excelencia de los individuos que el talento y la virtud. De estos mandatarios legales emanan leyes y cartas constitucionales así como las contribuciones o impuestos que no pueden promulgarse sino por aprobación de la nación misma o de sus representantes. Del mismo modo, las leyes deben ser claras, precisas y uniformes para todos los ciudadanos y mucho más teniendo en cuenta que los espíritus serviles interpretan la Escritura aplicándola a lo político y a lo militar, deduciendo de ella leyes inamovibles, haciendo bandera de esas interpretaciones, según las cuales para ganar su defensa inexpugnable, se inventaron que el poder real viene de Dios con el fin de la total impunidad frente a los ciudadanos. Es significativo por eso que una vez abordados otros varios temas, el libro retorne al tema fundamental en el último

tratadistas de Derecho procesal. Debían consultar la Curia Filípica de don Juan Hevia de Bolaños y las obras de don Ignacio Jordán de Asso y del Río y don Manuel y Rodríguez para adquirir un conocimiento bastante completo de la legislación castellana” (Leal, 1963: 199). 
capítulo, el LI, "El quasi religioso del dogma político de la soberanía del pueblo" (Roscio: 237), es decir, que si antes se evaluaba esta premisa para defenderla en los textos sagrados, en el capítulo final emerge el mismo concepto casi como dogma en la teoría del libro: "De muchos de los que siguen la trompeta del despotismo, podré yo deciros: Perdónalos Señor, porque no saben lo que hacen" (Roscio: 243) y siguiendo la misma pauta religiosa concluirá: "Ahora, Señor (diré yo), dejarás ir a tu siervo en paz, porque mis ojos han visto la libertad saludable de mi país, y de todos mis semejantes" (Roscio: 243).

Esta parte teórica del libro se entrevera con una serie de consideraciones acerca de la España que vivió y sufrió, en la que la imbricación iglesia y del estado dominaban las estructuras de poder. Por eso, y dado el carácter del libro, Roscio hablará a la vez de la iglesia y del estado despejando el diagnóstico para la situación histórica actual. Entiende que el funcionamiento de la España del momento es deudora de una Iglesia que abandonó la pobreza evangélica por el oro y las riquezas y llegó a tal poder que "Lo que al principio fue mera condescendencia con aquellos monarcas de quienes esperaban y recibían mercedes, y beneficios, fue después elevado a la clase de derecho pontificio" (Roscio: 170), de tal modo que ciertos reyes reunieron en su persona el poder del cielo y el poder de la tierra, confundiendo los valores espirituales y los temporales, haciendo uso de la presión inquisitorial y despojando al hombre de su libertad civil. Así uno de los iniciales poderes que el rey de España obtuvo, y que vuelve a recordar, es el poder sobre las tierras recién descubiertas mediante la ley de donación por parte de Alejandro VI. A este injusto procedimiento le sigue la instauración Inquisición, "que desviándose de su primitivo instituto, también metió la mano en los negocios de gobierno para reagravar las cadenas de la esclavitud" (Roscio: 172). Roscio da muestras de conocer y haber reflexionado en profundidad acerca de la historia de España, al dar cuenta de las desavenencias entre aragoneses y castellanos respecto a la Inquisición y cómo esa forma de gobierno se ha mantenido tanto en la península como en los territorios de América hasta hace pocos años en que las Cortes de Cádiz declararon la soberanía del pueblo. En cambio las cadenas de la esclavitud no se rompieron tan fácilmente en América y ofrece el testimonio de cómo "los Obispos e Inquisidores de México calificaban de herejes, y excomulgados a los que defendiesen este dogma político, o creyesen que el pueblo era soberano" (Roscio: 172). Algo que confiesa haber tenido noticia por un periódico de Londres, tal vez por El Español de su amigo Blanco White.

La España del pasado estaría representada en su obra, tanto por su propia cultura, adquirida con provecho en las instituciones coloniales, y cuyas lecturas deben mucho a su formación teológica y escolástica ${ }^{16}$, así como por la admiración que siente por

16 La Universidad de Caracas presentaba, según señala Ildefonso Leal, bastantes limitaciones y factores negativos en las enseñanzas, como la presencia tardía de los estudios de Medicina, el escaso número de Cátedras de Leyes, la ausencia de cátedras de física experimental y matemáticas y un exclusivo dominio de la filosofía aristotélica y tomista, aunque "a finales del siglo XVIII, [hacia el año 1788] gracias a los esfuerzos de Baltasar 
ciertos momentos históricos en los que los españoles fueron capaces de hacer valer su independencia y libertad. Por eso en algunos lugares de su libro insta a recorrer esa historia y procesar la diferencia de trato entre las actuaciones del pueblo español y la progresiva imposición de sus reyes, que fueron adquiriendo muy pronto, con la ayuda de la Iglesia un poder absoluto. España fue dominada por fenicios, cartagineses, romanos, y a ellos juraron vasallaje en el pasado, pero sus habitantes no dudaron en aliarse con los bárbaros en el momento de la invasión para deshacerse de ese yugo, así como más tarde combatirían la dominación musulmana para declarar de nuevo su libertad e independencia. Roscio destaca la formación de los otros reinos peninsulares y cómo Portugal acabó consiguiendo la separación de España, así como otros territorios adquirieron su libertad de los reyes castellanos. Como consecuencia nada extraño resulta que los territorios de América deseen materializar esa libertad: "Señalen los fanáticos y supersticiosos cuál es el lugar de las Santas Escrituras, del Nuevo y Viejo Testamento, donde haya Dios despojado al continente colombiano de aquel deber universal, inspirado a todos los hombres por su innata constitución" (Roscio: 80).

De este modo Roscio percibe el mal solapado que ha producido el desgobierno de los territorios españoles, al instituir una educación que coaccionaba las voluntades, que abusaba del procedimiento de las autoridades, que manipulaba los textos para consolidar el poder divino de los reyes, impidiendo así el ejercicio de la razón y de la libertad, en definitiva, la soberanía del pueblo. En efecto un mismo procedimiento educativo se impuso en la totalidad del imperio español del que fue víctima el propio autor que se introduce confesionalmente en el libro: "yo cursaba los estudios de la sagrada Escritura en las aulas permitidas por el gobierno opresivo de mi país", y continúa matizando, "La luz de la razón, los conocimientos del derecho natural y divino, eran el hilo de que todos carecíamos" (Roscio: 38). Es así como la alianza entre la teología y la jurisprudencia da lugar a una impunidad a ultranza de la monarquía que es defendida en los mismos estatutos universitarios:

Para los de España fue tan placentera esta condenación que, aceptándola en todas sus partes, la mandaron observar en las universidades y colegios, como punto cardinal de sus estatutos, ordenando que ninguno pudiese obtener cátedra ni grado literario sin que antes jurase no defender, ni aún como probable, la opinión del regicidio y tiranicidio que antes de Wiclef había enseñado el célebre Francisco Juan Petit, y sostuvieron posteriormente los jesuitas (Roscio: 76$)^{17}$.

Marrero, Francisco Pimentel, Alejandro Echezuría, Juan Agustín de la Torre y otros, la enseñanza universitaria se vio un tanto modernizada y ya el estudiantado comenzó a familiarizarse con las obras de Locke, Condillac, Malebranche, Lavoisier, Newton, Leibnitz, Cullen, Feijoo" (Leal, 1963: 84) Véase también Leal, 1983: 31).

${ }^{17}$ Esta idea del tiranicidio fue debatida en la escolástica medieval a partir de la lectura de Santo Tomás, posteriormente fue defendida en el siglo XVI por una parte de los juristas del momento, sobre todo los jesuitas, como Francisco Suárez y Juan de Mariana en De rege et regis institutione (1598), según el cual un ciudadano puede con justicia quitar la vida al rey 
Con todo, la crítica directa a la historia de España es más frecuente, desde la censura a los conquistadores que llegaron a América "escudados de falsas doctrinas nacidas en los siglos de oscuridad y desorden" (Roscio: 73) pasando por ese oscurantismo que se prolongó en la educación, pues solo se admitían los libros marcados dentro de esa pauta religiosa, y se los seleccionaba para condenar "la introducción y lectura de los que enseñaban la verdad. Era género de contrabando muy punible cualquier obra luminosa de política" (Roscio: 86). Como siempre en estos casos Roscio acumula sus experiencias y explicita sus percepciones y sus opiniones ("Yo hablo por experiencia propia" 95):

En lugar de esto, mientras yo cursaba las aulas llamadas de filosofía, teología, y derecho, oía con frecuencia defender en ellas, y en el teatro de las disputas solemnes, que el mejor de todos los gobiernos era el monárquico, tal como el que nos oprimía arbitrariamente. Ni de los libros de la Razón, ni de los Macabeos se tomaba jamás un argumento [...] y salía siempre triunfante la monarquía absoluta (Roscio: 100).

Bien veía el autor que el problema radicaba en la confusión deliberada de los poderes religioso y civil con lo que se hacía ver que cuanto ordenaba el rey era de voluntad divina y siempre lo más conveniente para la salud corporal y la salvación espiritual de los súbditos, pues con esa obediencia se conseguiría "el bien y prosperidad de la monarquía" (Roscio: 62). Y sin embargo, y en flagrante contradicción y doble moral, esa misma corona había recibido impuestos de las casas de prostitución:

En España eran derechos de la corona las contribuciones impuestas sobre casas públicas de meretrices: se arrendaba, se administraba este ramo de prostitución como cualquier otro de real hacienda. Duró este torpe ingreso hasta el reinado de Felipe IV en que fueron abolidos los lupanares españoles, cuyos derechos reales en cierta manera se recompensaron con los estancos introducidos en el mismo reinado (Roscio: 70$)^{18}$.

Si las críticas a España y su dominación menudean, también hay ejemplos de admiración. Para el prócer venezolano no todo es censurable sino que ciertos

que se convierte en tirano. Tal y como señala Roscio otros antecedentes conocidos están en John Winclef o Wynclif (1320-1384) antecesor del pensamiento reformista de Lutero, y Jean Petit que en 1408 justifica públicamente la muerte del duque de Orleans por parte del duque de Borgoña. Roscio, como otros hombres de su época cree que la expulsión de los jesuitas se debe a la defensa de ese pensamiento.

${ }^{18}$ En efecto, la Pragmática, Prohibición de mancebias y casas públicas de mugeres en todos los pueblos de estos reynos, fue dictada por Felipe IV en 1623 aunque tuvo corta duración y eficacia (Véase, Jean-Louis Guereña, La prostitución en la España contemporánea, Madrid, Marcial Pons, 2003, pp. 25-28). 
ejemplos del pueblo español resultan aleccionadores para el momento actual, así recuerda la fórmula que se acostumbraba entre los antiguos aragoneses, cuando investían a sus reyes: "Nos que valemos tanto como vos, y que todos juntos podemos más que vos, os hacemos Rey, si guardáredes nuestros fueros, franquezas y libertades; y si non, non" (Roscio: 40). Y en otro momento trae a su texto la rebelión de las Comunidades de Castilla y cómo las cortes castellanas negaron subsidios a los reyes (“¿No nos enseña la historia de Castilla, que aun cuando ya su constitución había sido herida por sus dos primeros monarcas Austríacos, todavía tuvieron bastante virtud sus Cortes para negarles subsidios que en la opinión de ellas no eran necesarios, ni útiles al procomunal del reino?", Roscio: 154). En este sentido se percibe que ha revisado la historia de España para hacer ver que su pasado antiguo y moderno presenta suficientes ejemplos en favor de los derechos del pueblo. En efecto, esta tendencia recala en el amplio capítulo XLIII, "Majestad del pueblo en antiguas leyes de España y en ciertos hechos de su historia", en el que hace gala de un amplio conocimiento de la historia de España y de sus leyes, empezando por las Partidas, de lectura obligatoria en los estudios de Leyes de la Universidad de Caracas, y donde se proclama, nos dice, que el rey no puede disponer de la hacienda de los súbditos: "Aquí se halla declarada la soberanía del pueblo, sin disputa, ni contradicción. En ninguna de las siete partidas se controvertió [sic] este dogma" (Roscio: 184). Añadiendo algo que le importaba mucho para demostrar el pervertimiento de la legalidad en el presente a causa de la confusión entre el trono y el altar: "Cuando los españoles formaban sus Leyes de Partida, gozaban del ejercicio de esta soberanía, como individuos de la misma especie que los Romanos" (Roscio: 184). Es cierto que la revisión que a partir de ese momento realiza de la historia de España, de la que saca conclusiones que favorecen la autoridad del pueblo, adolece de los tópicos de la época acerca de los visigodos y de reyes como Alfonso X, Enrique IV e Isabel I, pero favorece el pensamiento de ver cómo el autor valora las instituciones de esos primeros reinos que antecedieron al descubrimiento de la América, los Concilios de Toledo y las Cortes de Castilla y de Aragón, "Ninguna ley pasaba sin el otorgamiento espontáneo y libre de sus representantes" (Roscio: 186). Muy en especial valora el gobierno establecido en el reino de Aragón y la actitud de su pueblo que reclama la reparación de las injusticias y el reestablecimiento de la Inquisición porque para "los antiguos Aragoneses, toda la sangre del monarca irritado es insignificante e incapaz de intimidarlos" (Roscio: 187), con lo que recuerda los episodios relacionados con la muerte del inquisidor Pedro de Arbués en 1485 que, al contrario, trajeron nuevos males para los aragoneses. El descubrimiento del nuevo continente habría sido un acontecimiento nefasto para los reinos peninsulares y es a partir de entonces, con la entrada del oro y la plata del Nuevo Mundo, cuando la situación política empieza a pervertirse y da comienzo el despotismo monárquico.

A todo ello se añade la reflexión sobre la guerra de sucesión y la llegada de los Borbones, así como la guerra de la independencia, como hechos que marcan su presente y acerca de los que reflexiona con cuidado señalando los momentos de alarma y resistencia ante la tiranía extranjera, y, explotando el carácter testimonial del libro, hace énfasis en su credulidad acerca de unos reyes, que restituidos al trono, 
volvieron las cosas al estado anterior en que se hallaban: "Yo fui testigo del acontecimiento y fui también engañado en la perpetuidad de la reforma" (Roscio: 189); sobre todo después del tratado firmado en París en 1803 en que se reconoce la soberanía de los cantones suizos y no de la nación española. Todo ello lo corrobora el autor palpando el ambiente a través de los impresos de los clérigos absolutistas que alegando "los capítulos 8 de los Proverbios, 6 de la Sabiduría y 13 de la Carta de S. Pablo a los Romanos" (Roscio: 190) impedían el poder soberano de la nación española. Ello no haría sino reflejar la intromisión del papa en los asuntos políticos y seculares al convertir a seres ambiciosos en mandatarios plenipotenciarios o tiranos deificados que se consideran ungidos por Dios, de tal modo que se asemejan en su soberbia a la serpiente de Paraíso terrenal. Para terminar el análisis, Roscio aduce el que considera testimonio definitivo, el de la sucesión de Carlos II y el dictamen del papa favoreciendo al infante de Francia, nieto de Luis XIV, lo que provocó que el propio rey en su testamento lo apoyara en detrimento del Archiduque de Austria, de su propia casa reinante. Esta actitud desemboca en una guerra cruenta en la que, expresa con ironía, lo único que hará valer la soberanía del pueblo serán las armas. Roscio es por tanto absoluto partidario de la separación de la Iglesia y del Estado, porque ello va en detrimento de la soberanía del pueblo a uno y otro lado del mar. Por ello termina su reflexión llamando a la desconfianza a los conciudadanos: “¿Qué os podrán enseñar en este orden de cosas unos vasallos abyectos del tirano, unos declamadores y hechuras suyas?" (Roscio: 194).

Como puede percibirse la obra del autor venezolano adquiere un verdadero sentido en el momento de la emancipación, sus argumentos son fruto del momento y contienen un diagnóstico de importancia de la pugna entre absolutistas y liberales que marcaron ese comienzo pero también el resto del siglo.

\section{BIBLIOGRAFÍA}

BELLO, Andrés.

1984 Epistolario. Pról. de Oscar Sambrano Urdaneta. Caracas: La Casa de Bello, $2^{\mathrm{a}}$ edc., 2 vols.

Blanco White, José.

2007 Obra Completa. I Periódicos políticos. Vol. II. El Español. Ed. de Antonio Garnica Silva. Granada: Editorial ALMED.

GONZÁLEZ ORDOSGOITTI, Enrique Alí.

2007 "Juan Germán Roscio: Razones cristianas para la secesión de España", en AAVV, Miranda, Bolivar y Bello. Tres tiempos del pensar latinoamericano. VI Jornadas de Historia y Religión. Caracas: Universidad Católica Andrés Bello.

GOYTISOLO, Juan.

2010 Blanco White. El Español y la independencia de Hispanoamérica. Madrid: Taurus. 
GRASES, Pedro.

1964 “El 'Catecismo religioso político’ del Doctor Juan Germán Roscio”, Revista Nacional de Cultura (Separata del $\mathrm{n}^{\mathrm{o}}$ 161), Caracas: Ediciones del Ministerio de Educación.

LEAL, Ildefonso.

1963 Historia de la Universidad de Caracas (1727-1827). Caracas: Universidad Central de Venezuela-Ediciones de la Biblioteca.

1983 La Universidad de Caracas en los años de Bolívar. Caracas: Eds. del Rectorado de la UCV.

Morales PINO, Luz Ainai.

2008 Juan Germán Roscio: La subversión de la palabra. Caracas: Universidad Católica Andrés Bello.

1988 Pensamiento político de la emancipación venezolana. Comp., prol. y cron. de Pedro Grases. Caracas: Biblioteca Ayacucho..

PINO ITURRIETA, Elías.

2007 La mentalidad venezolana de la emancipación 1810-1812. Caracas: Bid. \& Co. Editor, $3^{\mathrm{a}}$ edc.

Roscio, Juan Germán.

1996 El triunfo de la libertad sobre el despotismo. Prol., cron. y bib. de Domingo Miliani. Caracas: Biblioteca Ayacucho.

ZAVALA, Silvio.

1944 Ensayos sobre la colonización española en América. Buenos Aires: Emecé.

1992 Por la senda hispana de la libertad. Madrid: Editorial Mapfre. 